\title{
Development of Antimalarial Phytomedicine of Artocarpus Champeden: a Model for Antimalarial Drugs Discovery
}

\author{
Aty Widyawaruyanti ${ }^{1,2, *}$
}

\author{
${ }^{I}$ Department of Pharmacognosy and Phytochemistry, Faculty of Pharmacy, Airlangga University, Dharmawangsa \\ Dalam, Surabaya-60286, Indonesia; ${ }^{2}$ Herbal Medicine Research Group, Institute of Tropical Disease, Airlangga \\ University, C Campus Mulyorejo, postal code, Indonesia
}

Malaria is a major public health problem in many tropical and subtropical countries including Indonesia and the burden of this disease is getting worse, mainly due to the increasing resistance of Plasmodium falciparum against the widely available antimalarial drugs. There is an urgent need for discovery of new antimalarial agents. Phytomedicines for the treatment of various diseases including malaria are an important part of the cultural diversity and traditions of which Indonesia's biodiversity has been an integral part. Artocarpus champeden Spreng. belongs to Moraceae family commonly known as "cempedak" was traditionally used for malarial remedies in Indonesia. This review focuses on antimalarial testing of ethanol extract of Artocarpus champeden stembark, identification of active compounds and development of A. Champeden stembark extract as a potential antimalarial phytomedicine. Ethanol extract of stembark of this plant showed a potential antimalarial activity both in vitro and in vivo and prospective to be developed as phytomedicine product for antimalarial. Identification of its actives compounds are needed as for standardization of the extract based on marker active compound. Some active compounds has been isolated and identified from this plant. Some of them are isoprenilated flavones and chalcone, including morachalcone as a marker active compound of A. champeden stembak ethanol extract. In order to develop A. champeden as antimalarial phytomedicine product with multi-component approach, standardized ethanol extract (ACEE) of A. champeden base on morachalcone as marker active compound was developed. This ACEE also has been formulated as granule in capsule dosage forms and each capsule containing $15 \mathrm{mg}$ ACEE in $300 \mathrm{mg}$ of granules, which is equivalent to $0.15 \mathrm{mg}$ morachalcone. In vivo experiment on parasite infected mice showed that the ACEE phytomedicine product was effective and safe. Mice treated with ACEE twice a day for three days before infection, continued for five days after infection in complementary with artesunat for three days, inhibited parasite $100 \%$. In this case, preventive effect of ACCE may be due to its immunostimulan activity that has been showed from the other experiment. Currently a clinical trial of this ACEE capsule in complementary with antimalarial standard drug artesunat being implemented at Maluku region, the endemic area of malarial disease in East Indonesia. An acquaintance with $\mathrm{A}$. champeden phytomedicine product may be a springboard for new phytotherapies that more affordable to treat malaria, especially among the less privileged native people living in endemic areas of the tropics, mostly at risk of this devastating disease.

Keyword: Artocarpus champeden, phytomedicine, antimalaria, morachalcone, marker active compound. 